\title{
Predictive control of induction motor drive
}

\author{
Ihor Kozakevych ${ }^{1, *}$, and Kyrylo Budnikov ${ }^{1}$ \\ ${ }^{1}$ Kryvyi Rih National University, Automatic Electromechanical Systems in Industry and Vehicles Department, 11 Vitalii Matusevych \\ Str., Kryvyi Rih, 50027, Ukraine
}

\begin{abstract}
The work is devoted to the study of the possibilities of using the predictive torque control system instead of the currently widely used direct torque control system. Aspects of using the system of direct torque control of an induction motor are considered and it is found that its significant disadvantage is the variable frequency of semiconductor switches. As a further development of the direct torque control system, a predictive torque control system is analyzed, which contains blocks for estimating unmeasured state variables, as well as predicting the state of a dynamic system when applying possible control signals. The systems were compared by mathematical modeling in Matlab / Simulink.
\end{abstract}

\section{Introduction}

Recently, the vector control system and the direct torque control system have proved to be the main control systems for AC electric drives $[1,2]$. The advantages of the latter include the ability to work without an angular velocity sensor on the shaft, simple structure and high dynamic quality control. At the same time, the main disadvantages of this system are the high level of torque ripple, which becomes especially sensitive when working at low angular velocity, as well as the presence of a variable switching frequency of power switches. A number of researchers' works in the field of automated electric drive are devoted to solving these problems. In [3], a modification of the direct torque control system was proposed, which is aimed at achieving a low level of torque ripples and ensuring a constant switching frequency of the power switches. In [4] the system of direct torque control with the involvement of neuro-phase technologies to achieve a low level of distortions of the motor current and its pulsations is investigated. In [5], a sliding mode system was used to implement sensorless control at very low angular velocities. In [6], the direct torque control system was supplemented by space-vector pulse-width modulation to obtain a constant switching frequency of the inverter switches. At the same time, it is easy to see that the further development of such systems requires more precision in controlling the values of stator flux coupling and torque. Therefore, currently predictive control systems for converters and electric drives are being actively developed [7].

Among such systems, the system of predictive torque control deserves special attention, which can be considered as an alternative to the system of direct torque control for electric drives with induction motors. To use such a system, it is necessary to use discrete models of the power converter and induction motor, and the values of stator flux and torque are considered as control variables of the system. The use of the mentioned discrete models allows to estimate and predict the values of stator flux linkage and torque, and further on the basis of these predictions the cost function is calculated, which allows to select the optimal control effect for the next discrete interval of the system. The synthesis of the cost function is carried out using weight coefficients that allow you to combine different sizes with each other and set priorities regarding their importance to achieve the desired control goal. Therefore, the quality of control of such systems depends very much on the choice of weight coefficients. Despite the fact that a number of publications have been devoted to the choice of weight coefficients $[8,9]$, this problem still remains relevant, as this step is important at the stage of synthesis of the electric drive control system.

\section{Direct torque control system}

The structure of the electric drive using the direct torque control system is shown in Fig. 1. In such a system, the induction motor is powered by a voltage-fed inverter. The task of the system is to provide the ability to independently control the values of the stator flux and motor torque by selecting the appropriate states of the inverter. As you know, a voltage-fed inverter is able to create 6 non-zero space voltage vectors, shifted by 60 degrees, as well as 2 zero voltage vectors. The system uses relay hysteresis torque and flux regulators, which allows to provide high dynamic control of the electric drive system, and expanding the width of the hysteresis allows to reduce the switching frequency of the inverter switches and, consequently, the power of losses in it.

The principle of direct torque control can be explained by considering the mathematical expression for the electromagnetic torque in the following notation:

$$
T_{e}=\frac{3}{2} p \frac{L_{m}}{L_{s} L_{r}}\left|\boldsymbol{\psi}_{s}\right| \cdot\left|\boldsymbol{\psi}_{r}\right| \sin (\theta)
$$

\footnotetext{
* Corresponding author: aepigor@gmail.com
} 


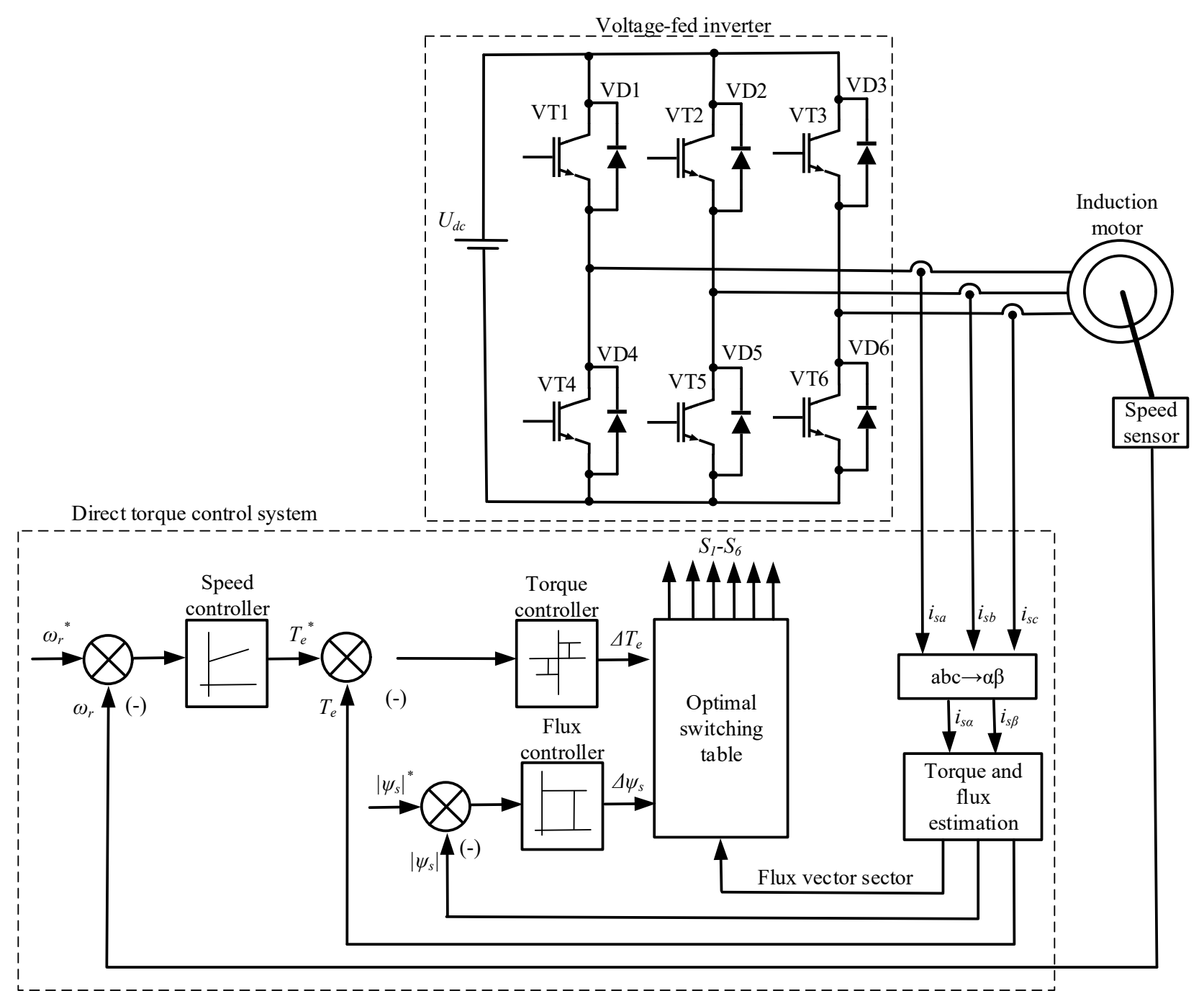

Fig. 1. Structure of direct torque control system.

where $p$ - the number of pole pairs; $L_{s}$ and $L_{r}-$ inductance of the stator and rotor windings of the motor, respectively; $L_{m}$ - mutual inductance of stator and rotor windings; $\boldsymbol{\psi}_{s}$ - flux linkage vector of the motor's stator windings; $\boldsymbol{\psi}_{r}$ - flux linkage vector of the motor's rotor winding; $\theta$ - angle between the flux linkage vectors of the stator and rotor.

It is believed that the stator flux vector reacts less inertially to the voltage applied to the motor windings, because the rotor time constant is significant. For simplicity, it is assumed that at one discrete interval of the system, the vector of flux linkage of the rotor is stationary. Therefore, the rotation of the stator flux vector in the direction of rotation leads to an increase in the value of the angle $\theta$ and increases the amount of torque. If the space voltage vector applied by the inverter causes the flux vector to rotate in the direction of convergence with the rotor flux vector, which will reduce the angle $\theta$, the torque generated by the motor will decrease. Since the stator flux linkage, when the value of the active resistance of the motor stator windings is small, can be found by integrating the voltage applied to the motor, the selection of the appropriate inverter voltage vector also allows to control the stator flux value. Thus, the use of a direct torque control system allows independent control of torque and stator flux linkage. The selection of the appropriate voltage vector and the state of the inverter switches is carried out using the table of optimal switching, which is presented in Table. 1.

Table 1. Switching table of direct torque control system of induction motor drive.

\begin{tabular}{|c|c|c|c|c|c|c|c|}
\hline \multirow{2}{*}{$\Delta \psi_{s}$} & \multirow{2}{*}{$\Delta T_{e}$} & \multicolumn{7}{|c|}{ Sectors } \\
\cline { 2 - 8 } & & 1 & 2 & 3 & 4 & 5 & 6 \\
\hline \multirow{3}{*}{1} & 1 & $U_{2}$ & $U_{3}$ & $U_{4}$ & $U_{5}$ & $U_{6}$ & $U_{1}$ \\
\cline { 2 - 8 } & 0 & $U_{0}$ & $U_{7}$ & $U_{0}$ & $U_{7}$ & $U_{0}$ & $U_{7}$ \\
\cline { 2 - 8 } & -1 & $U_{6}$ & $U_{1}$ & $U_{2}$ & $U_{3}$ & $U_{4}$ & $U_{5}$ \\
\hline \multirow{3}{*}{0} & 1 & $U_{3}$ & $U_{4}$ & $U_{5}$ & $U_{6}$ & $U_{1}$ & $U_{2}$ \\
\cline { 2 - 8 } & 0 & $U_{7}$ & $U_{0}$ & $U_{7}$ & $U_{0}$ & $U_{7}$ & $U_{0}$ \\
\cline { 2 - 8 } & -1 & $U_{5}$ & $U_{6}$ & $U_{1}$ & $U_{2}$ & $U_{3}$ & $U_{4}$ \\
\hline
\end{tabular}

\section{Predictive torque control system}

Predictive control systems for converters and electric drives are currently being actively developed. The principle of predictive control is to predict further changes in system state variables using a mathematical model of the system. In the next step, a certain optimization principle is used to compare possible options for changing 
the state of the system with each other in order to identify the most profitable in terms of achieving the ultimate goal of control. It is necessary to use a discrete model of the control object, which will allow you to predict changes in the state variable values.

The equations of electrical equilibrium of the stator circuits of the motor in a stationary frame of reference $\alpha \beta$ have the following form:

$$
\begin{aligned}
& \frac{d \psi_{s \alpha}}{d t}=U_{s \alpha}-R_{s} i_{s \alpha} \\
& \frac{d \psi_{s \beta}}{d t}=U_{s \beta}-R_{s} i_{s \beta},
\end{aligned}
$$

where $U_{s \alpha}, U_{s \beta}$ - projections of the stator voltage vector on the axis of the stationary coordinate system $\alpha \beta ; i_{s \alpha}, i_{s \beta}$ - projections of the stator current vector on the axis of the stationary coordinate system $\alpha \beta ; R_{s}$ - active resistance of the motor stator winding; $\psi_{s \alpha}, \psi_{s \beta}$ - projections of the stator flux vector on the axis of the stationary coordinate system $\alpha \beta$.

Convert equations (2) and (3) into a discrete form using Euler's method:

$$
\begin{aligned}
& \psi_{s \alpha}[n+1]=\psi_{s \alpha}[n]+U_{s \alpha}[n] \cdot \Delta t-R_{s} \cdot i_{s \alpha} \cdot \Delta t \\
& \psi_{s \beta}[n+1]=\psi_{s \beta}[n]+U_{s \beta}[n] \cdot \Delta t-R_{s} \cdot i_{s \beta} \cdot \Delta t
\end{aligned}
$$

where $\Delta t$ is the discrete time of the system.

The obtained equation allows to calculate the flux linkage of the stator $\psi_{s \alpha}[n+1]$, which refers to the discrete step $n+1$, based on the value of the flux linkage of the stator $\psi_{s \alpha}[n]$, which refers to the previous discrete step $n$.

The components of the flux vectors of the stator and rotor can be recorded through the appropriate inductances and currents:

$$
\begin{aligned}
& \psi_{s \alpha}=L_{s} i_{s \alpha}+L_{m} i_{r \alpha} ; \\
& \psi_{s \beta}=L_{s} i_{s \beta}+L_{m} i_{r \beta} ; \\
& \psi_{r \alpha}=L_{r} i_{r \alpha}+L_{m} i_{s \alpha} ; \\
& \psi_{r \beta}=L_{r} i_{r \beta}+L_{m} i_{s \beta},
\end{aligned}
$$

where $i_{r \alpha}, i_{r \beta}$ - projections of the rotor current vector on the axis of the stationary coordinate system $\alpha \beta$.

Since the rotor current is not a measurable value for motors with a short-circuited rotor, we get rid of its use through the combined use of equations (6) - (9):

$$
\begin{aligned}
& \psi_{s \alpha}=\left(L_{s}-\frac{L_{m}^{2}}{L_{r}}\right) i_{s \alpha}+\frac{L_{m}}{L_{r}} \psi_{r \alpha} ; \\
& \psi_{s \beta}=\left(L_{s}-\frac{L_{m}^{2}}{L_{r}}\right) i_{s \beta}+\frac{L_{m}}{L_{r}} \psi_{r \beta} .
\end{aligned}
$$

The dynamics of change of the components of the flux coupling vector of the rotor can be described by the following dependences:

$$
\begin{aligned}
& \frac{d \psi_{r \alpha}}{d t}=-\frac{R_{r}}{L_{r}} \psi_{r \alpha}+\frac{L_{m} R_{r}}{L_{r}} i_{s \alpha}-\omega_{r} \psi_{r \beta} ; \\
& \frac{d \psi_{r \beta}}{d t}=-\frac{R_{r}}{L_{r}} \psi_{r \beta}+\frac{L_{m} R_{r}}{L_{r}} i_{s \beta}+\omega_{r} \psi_{r \alpha} .
\end{aligned}
$$

where $R_{r}$ - the active resistance of the motor rotor winding, $\omega$ - the angular velocity of rotation of the rotor.

Using the Euler method, the prediction of the stator current can be performed in accordance with the following dependencies:

$$
\begin{gathered}
i_{s \alpha}[n+1]=\left(1-\frac{\Delta t\left(R_{s} L_{r}^{2}+R_{r} L_{m}^{2}\right)}{L_{r}\left(L_{s} L_{r}-L_{m}^{2}\right)}\right) \cdot i_{s \alpha}[n]+ \\
+\frac{\Delta t\left(R_{s} L_{r}^{2}+R_{r} L_{m}^{2}\right)}{\Delta t\left(R_{s} L_{r}^{2}+R_{r} L_{m}^{2}\right)+L_{r}\left(L_{s} L_{r}-L_{m}^{2}\right)} u_{s \alpha}[n]+ \\
+\frac{\Delta t L_{m} R_{r}}{\Delta t\left(R_{s} L_{r}^{2}+R_{r} L_{m}^{2}\right)+L_{r}\left(L_{s} L_{r}-L_{m}^{2}\right)} \psi_{s \alpha}[n]+ \\
\quad+\frac{\Delta t L_{m} L_{r} \omega}{\Delta t\left(R_{s} L_{r}^{2}+R_{r} L_{m}^{2}\right)+L_{r}\left(L_{s} L_{r}-L_{m}^{2}\right)} \psi_{s \beta}[n] ; \\
i_{s \beta}[n+1]=\left(1-\frac{\Delta t\left(R_{s} L_{r}^{2}+R_{r} L_{m}^{2}\right)}{L_{r}\left(L_{s} L_{r}-L_{m}^{2}\right)}\right) \cdot i_{s \beta}[n]+ \\
+\frac{\Delta t\left(R_{s} L_{r}^{2}+R_{r} L_{m}^{2}\right)}{\Delta t\left(R_{s} L_{r}^{2}+R_{r} L_{m}^{2}\right)+L_{r}\left(L_{s} L_{r}-L_{m}^{2}\right)} u_{s \beta}[n]+ \\
+\frac{\Delta t L_{m} R_{r}}{\Delta t\left(R_{s} L_{r}^{2}+R_{r} L_{m}^{2}\right)+L_{r}\left(L_{s} L_{r}-L_{m}^{2}\right)} \psi_{s \beta}[n]- \\
-\frac{\Delta t L_{m} L_{r} \omega}{\Delta t\left(R_{s} L_{r}^{2}+R_{r} L_{m}^{2}\right)+L_{r}\left(L_{s} L_{r}-L_{m}^{2}\right)} \psi_{s \alpha}[n] ;
\end{gathered}
$$

Prediction of the value of the electromagnetic torque can be obtained using the predicted values of the stator flux and stator current:

$$
\begin{gathered}
T_{e}[n+1]=\frac{3}{2} p \times \\
\times\left(\psi_{s \alpha}[n+1] i_{s \beta}[n+1]-\psi_{s \beta}[n+1] i_{s \alpha}[n+1]\right),
\end{gathered}
$$

where $p$ is the number of pole pairs.

The cost function is composed using the deviations of the torque value from the specified value and the deviation of the modulus of the flux linkage vector from the corresponding rated level:

$$
\begin{gathered}
c=\left|T_{e}[n+1]-T_{e}^{*}\right|+ \\
+\left.w_{\psi}\left|\sqrt{\psi_{s \alpha}^{2}[n+1]+\psi_{s \beta}^{2}[n+1]}-\right| \boldsymbol{\psi}_{s}\right|^{*} \mid .
\end{gathered}
$$

where $w_{\psi}-$ a weighting factor that reflects the relative importance of flux control in relation to torque control. As the initial setting of this parameter it is advisable to use the following value:

$$
w_{\psi}=\frac{T_{\text {rated }}}{\psi_{\text {srated }}}
$$

where $T_{\text {rated }}$ - the value of the rated torque of the motor; $\psi_{\text {srated }}$ - rated value of stator flux linkage.

The structure of the system of predictive torque control of an induction motor is presented in Fig. 2. By analogy with the previous system, the torque reference signal is formed by the PI controller, and the magnitude of the stator flux linkage when operating at a speed lower than the rated, usually set at the nominal level and 
attenuated when switching to higher nominal. Based on the measured values of motor current and voltage, the values of the torque and flux linkage of the stator are estimated, because the direct measurement of these values is difficult to implement. Based on the obtained equations, the values of motor torque and stator flux coupling are predicted by applying each of the eight possible voltage vectors generated by the voltage inverter. In accordance with equation (17) get eight values of the objective function, from which the minimum value is selected and in the next interval of discreteness of the system, the inverter applies to the motor a vector with a number corresponding to the obtained minimum value of the objective function.

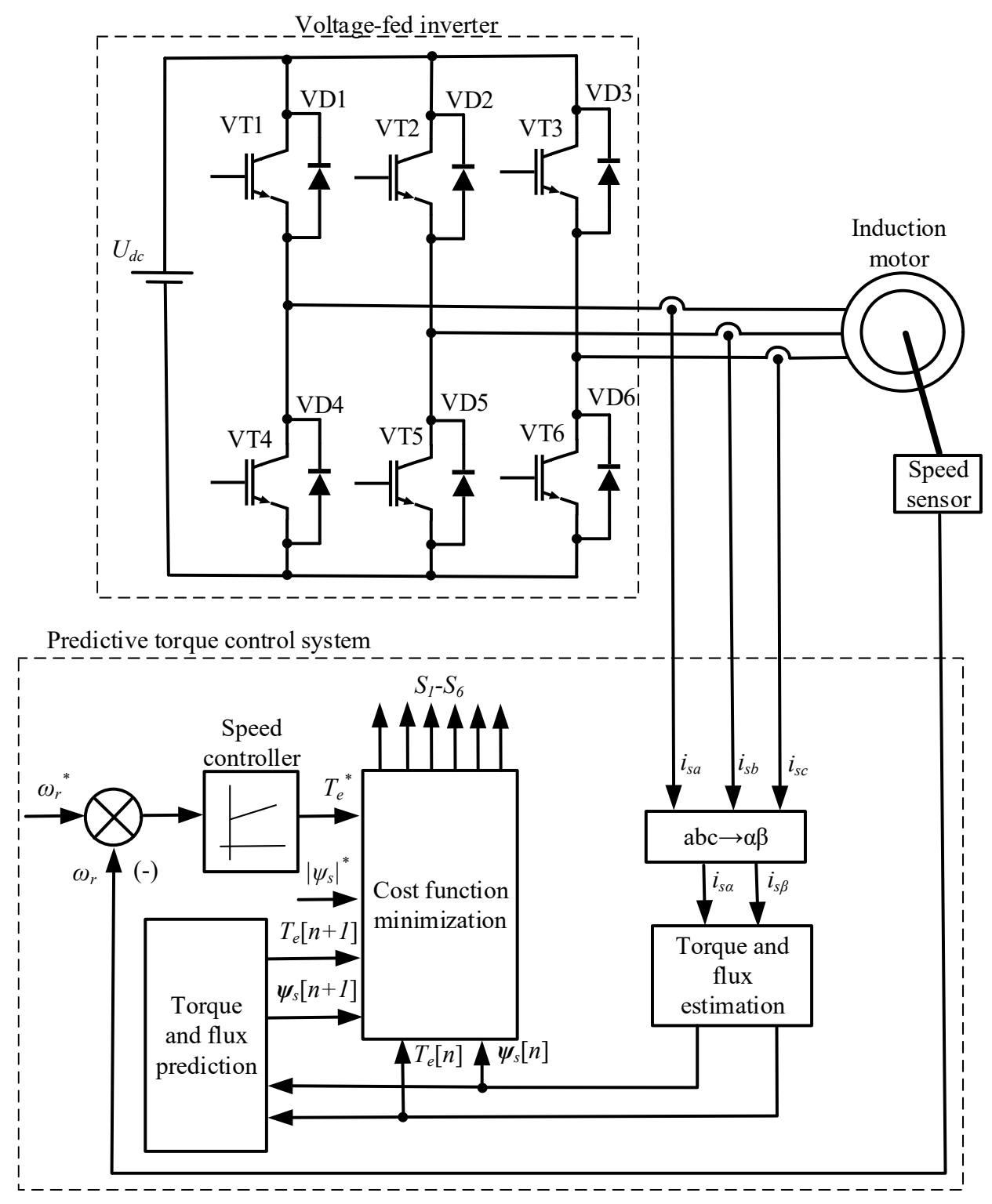

Fig. 2. Structure of predictive torque control system.

\section{Simulation results}

A mathematical model in the Matlab / Simulink environment was developed to analyze the predictive torque control system of an induction motor. The parameters of the engine used in the simulation are given in Table 2.

Fig. 3 shows a comparison of motor torques when using direct torque control and predictive torque control in steady state operation. The graphs show that the use of predictive control reduces the level of torque ripple.
Table 2. Switching table of direct torque control system of induction motor drive.

\begin{tabular}{|l|l|}
\hline \multicolumn{1}{|c|}{ Parameter name } & $\begin{array}{l}\text { Parameter } \\
\text { value }\end{array}$ \\
\hline Rated power $P_{\text {rated }}$ & $75 \mathrm{~kW}$ \\
\hline Number of pole pairs, $p$ & 2 \\
\hline Active resistance of the stator winding, $R_{S}$ & $0.035 \mathrm{Ohm}$ \\
\hline Active resistance of the rotor winding, $R_{r}$ & $0.021 \mathrm{Ohm}$ \\
\hline Leakage inductance of the stator winding, $L_{\sigma S}$ & $330 \mathrm{mH}$ \\
\hline Leakage inductance of the rotor winding, $L_{\sigma r}$ & $330 \mathrm{mH}$ \\
\hline $\begin{array}{l}\text { Mutual inductance of stator and rotor windings, } \\
L_{m}\end{array}$ & $0.015 \mathrm{H}$ \\
\hline
\end{tabular}


Fig. 4 shows the shape of the currents flowing through the stator windings. They show that the use of predictive control reduces the distortion of the current shape, increasing the energy efficiency of electromechanical equipment.
Fig. 5 shows the response of the system to changes in load torque. The graphs show that the predictive control system has a higher speed.
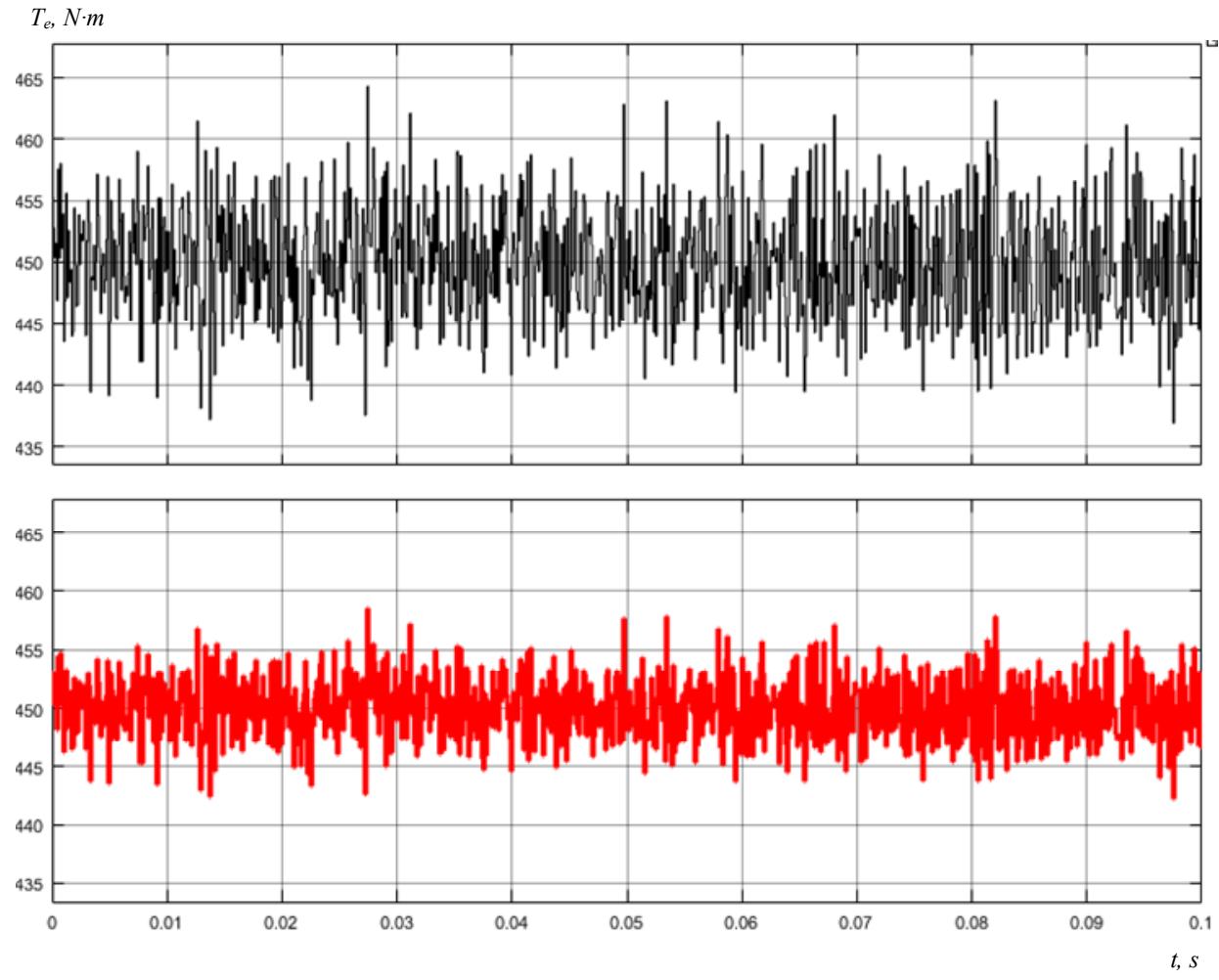

Fig. 3. Motor torque in steady-state with direct torque control system (top) and predictive torque control system (bottom).
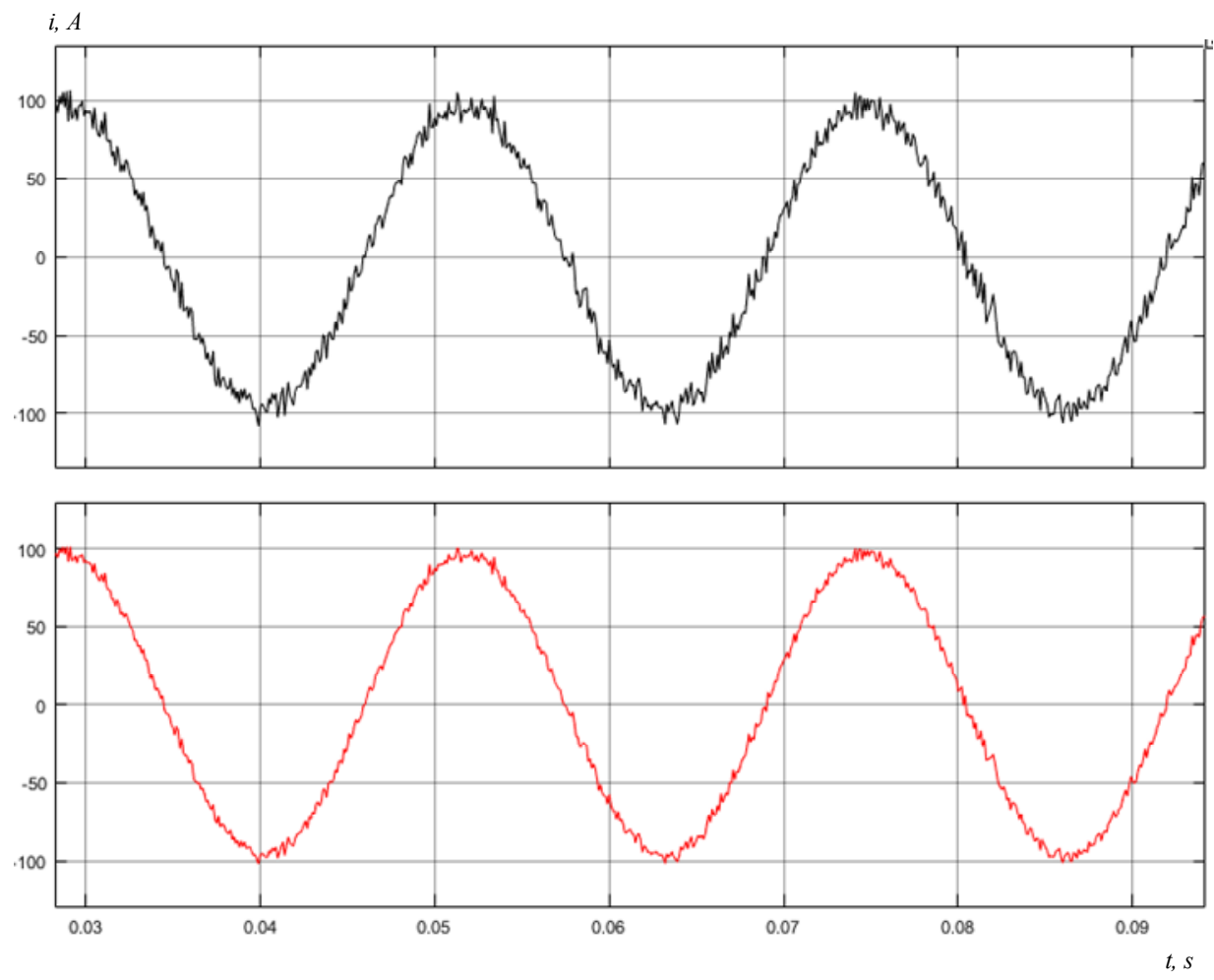

Fig. 4. Motor current in steady-state with direct torque control system (1) and predictive torque control system (2). 

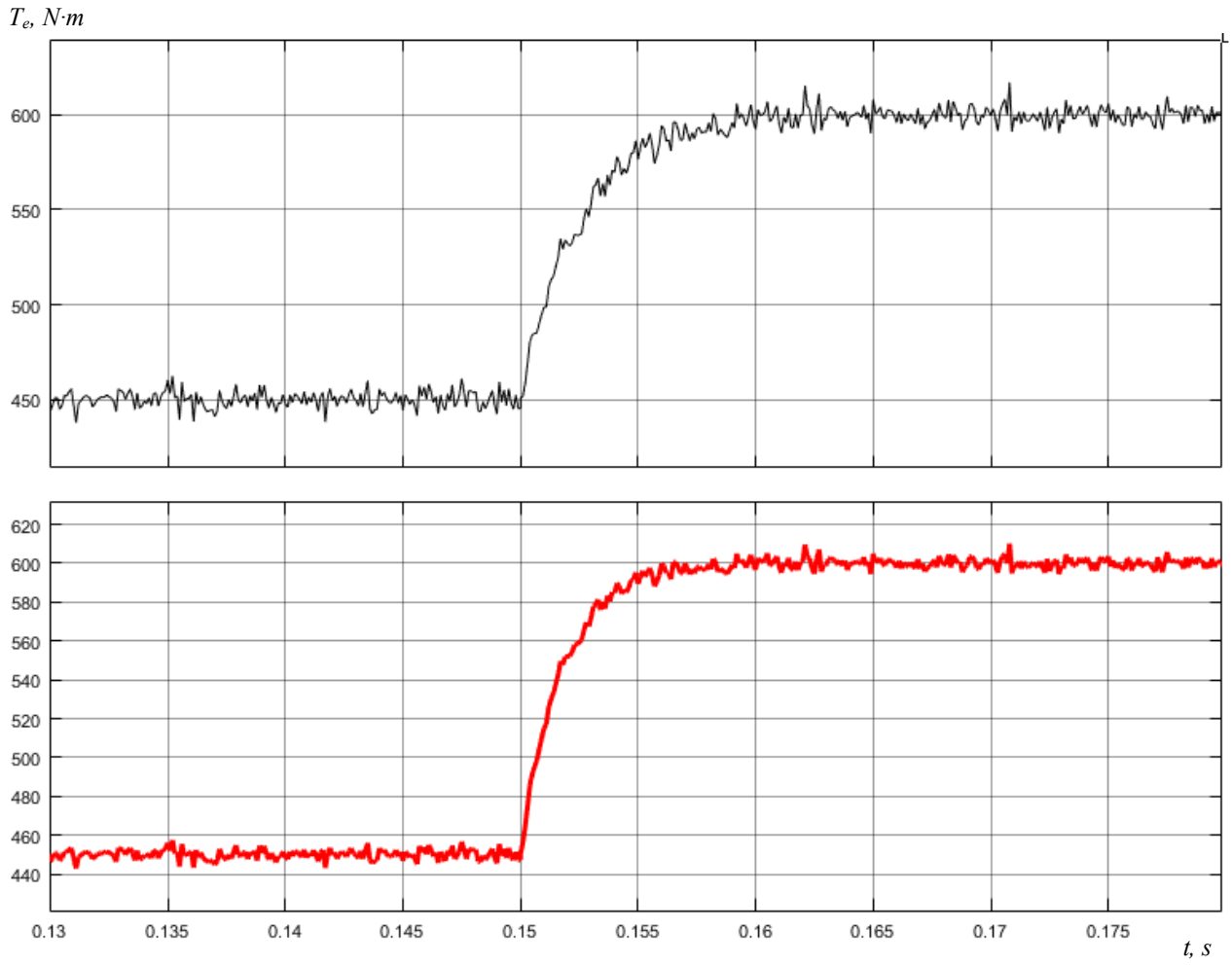

Fig. 5. Motor torque when load torque changes with direct torque control system (top) and predictive torque control system (bottom).

\section{Conclusions}

The paper considers the system of direct torque control and the predictive torque control system of an induction motor. The direct torque control system selects the voltage vector based on pre-calculated rules that allow to take into account the sector to which the stator flux vector currently falls, as well as the output signals of two relay hysteresis regulators - stator flux regulator and motor torque regulator. This structure allows this system to have a simpler structure compared to the vector control system, eliminating the need to use coordinate transducers. However, a significant disadvantage of the direct torque control system is the variable switching frequency of the keys and the presence of a noticeable torque ripple. A variant of predictive torque control of an induction motor is considered, which contains a discrete mathematical model for calculating the predicted values of stator current, stator flux and torque for the next step of the system discreteness. Since the number of voltage vectors generated by the voltage inverter is limited, it is possible to calculate the value of the objective function for each variant of the control effect. In the future, the choice of option that corresponds to the minimum value of this function. To compare the two systems, mathematical modeling was performed in the Matlab / Simulink environment, which showed that the use of predictive control reduces the level of torque ripple and improves the dynamic control of the electric drive. In the subsequent stages of research it is necessary to carry out the analysis of influence of deviations of parameters of the engine on indicators of system of predictive control.

\section{References}

1. S.-K. Sul, Control of electric machine drive systems (Wiley-IEEE Press, 2011)

2. B. $\mathrm{Wu}, \mathrm{M}$. Narimani, High-power converters and $A C$ drives (Wiley-IEEE Press, 2017)

3. J. Kang, S. Sul, New direct torque control of induction motor for minimum torque ripple and constant switching frequency. IEEE Trans. on Industry Applications 35/5, 1076-1082 (1999)

4. P. Z. Grabowski, F. Blaabjerg, Direct torque neurofuzzy control of induction motor drive. DSP implementation, in Proc. Of the 24th Ann. Conf. of the IEEE IECON, pp. 657-661 (1998)

5. C. Lascu, I. Boldea, F. Blaabjerg, Direct torque control of sensorless induction motor drives: a sliding-mode approach. IEEE Trans. on Industry Applications 40/2, 582-590 (2004)

6. Y. Lai, J. Chen, A new approach to direct torque control of induction motor drives for constant inverter switching frequency and torque ripple reduction. IEEE Trans. on Energy Conversion 16/3, 220-227 (2001)

7. P. Cortes, M. P. Kazmierkowski, R. M. Kennel, D. E. Quevedo, J. Rodriguez, Predictive control in power electronics and drives. IEEE Trans. on Industrial Electronics 55/12, 4312-4324 (2008)

8. F. Wang, Z. Zhang, A. Davari, J. Rodriguez, R. Kennel, An experimental assessment of finitestate predictive torque control for electrical drives by considering different online-optimization methods. Control Engineering Practice 31, 1-8 (2014) 
9. F. Wang, S. Li, X. Mei, W. Xie, J. Rodriguez, R. M. Kennel, Model based predictive direct control strategies for electrical drives: an experimental evaluation of PTC and PCC methods. IEEE Trans. on Industry Informatics 11/3, 671-681 (2015)

10. I. Kozakevich, Investigation of the direct torque control system of an electromechanical system with a matrix converter, in Proc. of the Intern. Conf. on Modern Electrical and Energy Systems, pp. 228-231 (2017)

11. Š. Janouš, J. Talla, V. Šmídl, Z. Peroutka, Model Predictive Control of Dual Induction Motor Single Inverter Drive, in 2018 18th Int. Conf. on Mechatronics - Mechatronika, Czech Republic (2018)

12. T. Kosan, J. Talla, S. Janous, V. Blahnik, FPGABased Accelerator for Model Predictive Control of Induction Motor Drive, in 18th Int. Conf. on Mechatronics - Mechatronika, Czech Republic (2018)

13. Z. Zhao, Z. Ruan, D. Meng, Y. Xue, C. Gu, Sliding Mode Observer Based Sensorless Model Predictive Current Control for Induction Motor, in IEEE 2nd Int. Conf. on Power and Energy Applications, Singapore, pp. 84-88 (2019)

14. Z. Yin, Y. Zhang, X. Tong, Y. Zhong, Model Predictive Control Using Globe Exponential Reaching Law Sliding Mode Design Method for Induction Motor Drives, in IEEE Applied Power Electronics Conference and Exposition, USA, pp. 2559-2563 (2019)

15. Z. Yin, W. Li, Y. Zhang, R. Tang, Model Predictive Torque Control Based on a Disturbance Observer for Induction Motor Drives, in 14th IEEE Conf. on Industrial Electronics and Applications, China, pp. 1871-1875 (2019)

16. I. Kozakevych, R. Siyanko, Simulation of processes in the modular multilevel inverter, in Proc. of the Intern. Conf. on Modern Electrical and Energy Systems, pp. 386-389 (2019)

17. P. Karlovsky, J. Lettl, Loss Reduction in Induction Motor Drive Using Model Predictive Control, in 10th International Conference on Electronics, Computers and Artificial Intelligence, Romania, pp. 1-4 (2018)

18. X. Wang, Y. Zhang, H. Yang, B. Zhang, J. Rodriguez, A Robust Predictive Current Control of Induction Motor Drives, in IEEE Energy Conversion Congress and Exposition, USA, pp. 5136-5140 (2020)

19. O. Sinchuk, I. Kozakevich, Research of regenerative braking of traction permanent magnet synchronous motors, in Proc. of the Intern. Conf. on Modern Electrical and Energy Systems, pp. 92-95 (2017)

20. Y. Xue, D. Meng, Z. Zhao, L. Zhao, L. Diao, Model Predictive Current Control in the Stationary Coordinate System for a Three-Phase Induction Motor Fed by a Two-Level Inverter, in IEEE Int. Symp. on Predictive Control of Electrical Drives and Power Electronics, China, pp. 1-5 (2019)
21. A. A. Adam, Y. Haroen, A. Purwadi, A. S. Rohman, A Study of a Three Phase Induction Motor Performances Controlled by Indirect Vector and Predictive Torque Control, in 5th Int. Conf. on Electric Vehicular Technology, Indonesia, pp. 204209 (2018)

22. O. Sinchuk, I. Kozakevych, Control system of double-rotor induction motors for hybrid vehicles. Nauk. Visn. Natsional. Hirnych. Univers. 2019/2, $72-$ 78 (2019)

23. A. Bhowate, M. Aware, S. Sharma, Y. Tatte, Predictive Torque Control for Five Phase Induction Motor Drive with Common Mode Voltage Reduction, in Int. Power Electronics Conf., Niigata, pp. 1730-1735 (2018)

24. O. Sinchuk et al, Research of PMSM wind generator under asymmetry grid conditions, in Proc. of Int. Conf. on Modern Electrical and Energy Systems, pp. 278-281 (2019)

25. Y. Zhang, Z. Yin, W. Li, X. Tong, Y. Zhong, Speed Sensorless Model Predictive Control Based on Disturbance Observer for Induction Motor Drives, in IEEE Int. Symp. on Predictive Control of Electrical Drives and Power Electronics, China, pp. 1-4 (2019)

26. K. V. P. Kumar, T. V. Kumar, Predictive torque control strategy of an Open-End Winding Induction Motor Drive with less common-mode voltage, in IEEE Int. Conf. on Industrial Technology, Lyon, pp. 498-503 (2018)

27. S. Azadi, S. A. Davari, A. Aghili Ashtiani, C. Garcia, J. Rodrigues, Reducing Variation of Switching Frequency in Finite-State Predictive Torque of threePhase Induction Motor, in 10th Int. Power Electronics, Drive Systems and Technologies Conf., Iran, pp. 108-113 (2019)

28. Z. Wang, Z. Zheng, Y. Li, J. Sun, Z. Deng, A robust offset-free model predictive current control for induction motor based on incremental model and incremental current observer, in IEEE Int. Symp. on Predictive Control of Electrical Drives and Power Electronics, China, pp. 1-5 (2019)

29. Y. Lu, J. Zhao, A sliding mode flux observer for predictive torque controlled induction motor drive, in Chinese Control And Decision Conf., Shenyang, pp. 3280-3285 (2018)

30. Q. Chen, R. Kennel, Variable Switching Point Parallel Predictive Current Control (VSP3CC) for Induction Motor, in 22nd European Conf. on Power Electronics and Applications, France, pp. 1-9 (2020)

31. İ. Şahin, O. Keysan, E. Monmasson, Experimental tuning and design guidelines of a dynamically reconfigured weighting factor for the predictive torque control of an induction motor, in 22nd European Conf. on Power Electronics and Applications, France, pp. 1-8 (2020)

32. A. Bhowate, M. Aware, S. Sharma, Rank Ordering Criteria Based Weighting Factor Evaluation in Model Predictive Torque Control of Five-phase Induction Motor Drive, in IEEE Int. Conf. on Power 
Electronics, Drives and Energy Systems, India, pp. 15 (2018)

33. S. M. Muslem Uddin, G. Mirzaeva, A High Performance Feedback Quantized Predictive Control of Induction Machine Drives, in IEEE Energy Conversion Congress and Exposition, USA, pp. 5930-5935 (2020)

34. Y. Mei, L. Wang, W. Huang, An Improved Model Predictive Control Method for Induction Motor Drives Fed by Indirect Matrix Converter, in IEEE Int. Power Electronics and Application Conf. and Exposition, pp. 1-5 (2018)

35. V. Kavana, M. Neethi, Fault Analysis and Predictive Maintenance of Induction Motor Using Machine Learning, in Int. Conf. on Electrical, Electronics, Communication, Computer, and Optimization Techniques, India, pp. 963-966 (2018)

36. A. Bhowate, M. Aware, S. Sharma, Synthetic Voltage Vector Selection Criteria in Predictive Torque Control for Performance Improvement of Three Phase Induction Motor Drive, in 10th Int. Conf. on Power Electronics and ECCE Asia, Korea (South), pp. 1263-1267 (2019)

37. N. Arun, M. Aware, A. Bhowate, Predictive Torque Control of 5-Phase Series Connected Induction Motor Drives, in 15th IEEE India Council Int. Conf., India, pp. 1-5 (2018)

38. A. Ammar, A. Kheldoun, B. Metidji, B. Talbi, T. Ameid, Y. Azzoug, An Experimental Assessment of Direct Torque Control and Model Predictive Control Methods for Induction Machine Drive, in Int. Conf. on Electrical Sciences and Technologies in Maghreb, Algiers, pp. 1-6 (2018)

39. D. Wu, J. Chen, R. Zhu, G. Hua, Simplified Model Predictive Flux Control for Dual Inverter Fed Open End Winding Induction Motor, in IEEE 10th Int. Symp. on Power Electronics for Distributed Generation Systems, pp. 1050-1054 (2019)

40. F. Stinga, M. Marian, Estimation and Nonlinear Predictive Control for an Induction Machine, in 6th Int. Conf. on Control, Decision and Information Technologies, France, pp. 494-499 (2019)

41. A. I. Soliman, A. Farhan, M. Abdelrahem, R. Kennel, Enhanced Sensorless Model Predictive Control of Induction Motor Based on Extended Kalman Filter, in IEEE Conf. on Power Electronics and Renewable Energy, Egypt, pp. 309-313 (2019)

42. A. Hota, M. Qasim, J. L. Kirtley, V. Agarwal, A Low Cost Electrolytic Capacitor-less Induction Motor Drive Based on a Novel Open Loop Model Predictive Control Strategy, in Innovations in Power and Advanced Computing Technologies, India, pp. 1-5 (2019)

43. Y. Lim, J. Lee, K. Lee, Improved Model Predictive Control Method for Two Induction Motor Fed by Five-Leg Inverter System, in IEEE Energy Conversion Congress and Exposition, pp. 4552-4557 (2018)
44. M. F. Elmorshedy, W. Xu, Y. Liu, S. M. Allam, M. Dong, Speed Control of Linear Induction Motor based on Finite-Set Model Predictive Direct Flux Control, in IEEE Int. Symp. on Predictive Control of Electrical Drives and Power Electronics, China, pp. 1-6 (2019)

45. Y. Zhang, X. Wang, B. Zhang, H. Yang, A Robust Model-Free Predictive Current Control of Induction Motor Drives, in 22nd Int. Conf. on Electrical Machines and Systems, China, pp. 1-5 (2019)

46. I. Sami, B. Khan, R. Asghar, C. A. Mehmood, S. M. Ali, Z. Ullah, A. Basit, Sliding Mode-Based Model Predictive Torque Control of Induction Machine, in Int. Conf. on Engineering and Emerging Technologies, Pakistan, pp. 1-5 (2019)

47. J. Su, R. Gao, I. Husain, Model Predictive Control Based Field-Weakening Strategy for Traction EV Used Induction Motor, in IEEE Trans. on Ind. Appl. 54/3, pp. 2295-2305 (2018)

48. J. A. Corral-Hernandez, J. A. Antonino-Daviu, Thorough validation of a rotor fault diagnosis methodology in laboratory and field soft-started induction motors. Ch. Journ. of Electr. Eng. 4/3, 6672 (2018)

49. H. Xie, Q. Chen, Y. Tang, R. Kennel, F. Wang, A. Xia, Z. Zhang, J. Rodriguez, Sliding-Mode MRAS based Encoderless Predictive Torque Control for Induction Machine, in IEEE Int. Symposium on Predictive Control of Electrical Drives and Power Electronics, China, pp. 1-4 (2019)

50. Y. Mei, L. Wang, W. Huang, S. Niu, An Improved Zero Current Commutation Model Predictive Torque Control Method for the Induction Motor Drives Fed by Indirect Matrix Converter, in 21st Int. Conf. on Electrical Machines and Systems, pp. 1476-1480 (2018) 